\title{
NONLINEAR LIAPUNOV DYNAMICS
}

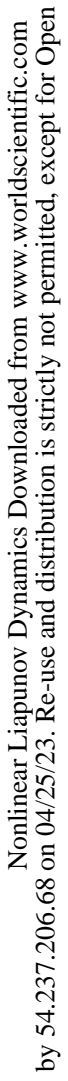


Also by J M Skowronski

Control Theory of Robotic Systems

(World Scientific Series in Computer Science - Vol. 11) 

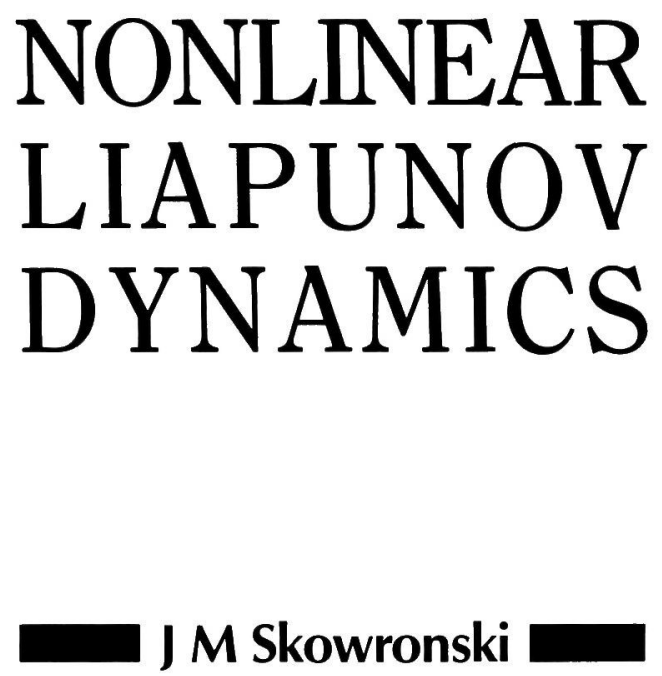

University of Southern California.

Los Angeles, California and

University of Queensland

St. Lucia, Australia 
Published by

World Scientific Publishing Co. Pte. Ltd.

P O Box 128, Farrer Road, Singapore 9128

USA office: 687 Hartwell Street, Teaneck, NJ 07666

UK office: 73 Lynton Mead, Totteridge, London N20 8DH

Library of Congress Cataloging-in-Publication data is available.

\section{NONLINEAR LIAPUNOV DYNAMICS}

Copyright $\odot 1990$ by World Scientific Publishing Co. Pte. Ltd.

All rights reserved. This book, or parts thereof, may not be reproduced in any form or by any means, electronic or mechanical, including photocopying, recording or any information storage and retrieval system now known or to be invented, without written permission from the Publisher.

ISBN 981-02-0192-3

Printed in Singapore by Utopia Press. 


\section{PREFACE}

Realistic models of the physical world are nonlinear, involving large amplitudes of motion and thus usually several equilibria of the system concerned. Hence in the majority of applications nonlinearities may not be truncated without seriously effecting the adequacy of the model. In spite of this, nonlinear dynamics has remained without much interface with applications for a long time. The reason for this seems to be at least two-fold. First, there was lack of practical methods implementing the nonlinear results in everyday applied dynamics. Second, the massive investment of time and resources in the linearized techniques generated a potent disincentive for the change, even at the expense of accurate modelling. The first aspect lost its ground with the arrival of fast computers, but the second still persists. Indeed, changes in the attitudes of people are always slower than changes in technology. There is, however, good news. Not only is nonlinear dynamics stimulated by computers, but the converse occurs as well. The nonlinear techniques speed up computation by identifying the types of dynamic trajectories concerned and, perhaps even more importantly, by helping to check the results. Furthermore, the Liapunov formalism, fundamental for nonlinear dynamics, becomes an essential part of the theory of parallel computing and neural networks. The latter are presently successfully replacing artificial intelligence and expert systems in most progressive applications, and thus generating considerable demand for Liapunov type algorithms and for nonlinear dynamics in general.

The book gives the Liapunov background for the analysis and synthesis (design) of dynamic behaviour of general networks which represent 
a large class of nonlinear systems, predominantly physical, and in particular mechanical. It is meant to be a self-learning and thought provoking reference text. It has grown from junior graduate level lectures in Engineering Science and Applied Mathematics over a number of years at several universities (Notre Dame, Ottawa, Queensland, Alberta, Southern California) and circulated for a while in the format of lecture notes. The first, introductory chapter refers to the basic concepts of static characteristics and dynamic processes. The second and third describe various formats of dynamic models and give a reference frame for their behaviour. The fourth chapter introduces basic energy relations, fundamental to the dynamic use of the Liapunov method. The method itself is described in chapter five, with implementations in chapters six and seven. The methods of Liapunov Design (synthesis) and Control in chapter eight close the text.

The prerequisite background is not above elementary analytic dynamics (mechanics) and differential equations. Readers not interested in the systems interpretation of dynamics may leave out the first chapter without consequence to later reading. On the other hand chapters four and five are fundamental to the whole text. The material is slightly longer than for a semester course, giving the instructor the option of cutting off some sections which are less useful to his particular group of students.

The author is indebted to his wife Elzbieta and children, Joanna and Michal for their patience and help while writing this text.

Los Angeles, January 1990 
TABLE OF CONTENTS

Preface

CHAPTER 1: STRUCTURES IN SYSTEM DYNAMICS

1.1 An 0scillator

1.2 The Meta-Structure

1.2.1 States

1.2.2 Events

1.2.3 Organization 14

$\begin{array}{ll}1.2 .4 & \text { Autonomy } \\ 1.2 .5 & 19\end{array}$

1.2.5 Evolution 24

1.2.6 Input-Output Representation 28

$\begin{array}{lll}1.3 & \text { Literature } & 33\end{array}$

References 1

CHAPTER 2: LUMPED MODEL

2.1 The Network

2.1.1 Configuration

2.1.2 Static Network

2.1.3 Types of Characteristics 53

2.1.4 Kinetic Network 58

2.2 The Equations of Evolution 61

2.2.1 Basic Forms 61

2.2.2 Polyflow 68

$\begin{array}{ll}2.3 \text { The Frame of Reference } & 71\end{array}$

2.3.1 Autonomous Processes 71

2.3.2 Integrable Reference System 77

$\begin{array}{lll}2.3 .3 & \text { Energy } & 84\end{array}$

2.4 An Ecological Example 90

2.4.1 Lotka-Volterra Model 90

2.4.2 Non-Conservative Model 93

$\begin{array}{ll}\text { References } 2 & 96\end{array}$

CHAPTER 3: SYMPLECTIC PHYSICAL MODEL 101-155

3.1 General Description of the Model 101

$\begin{array}{lll}3.1 .1 & \text { Equations } & 101\end{array}$

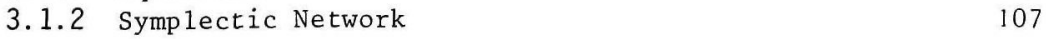


3.2 The Restitutive Characteristics

3.2.1 Physical and Geometric Shape of Restitution 112

3.2.2 Conservative Reference System 126

3.3 The Non-Conservative Actions 136

3.3.1 Types of Actions 136

3.3.2 Damping 138

3.3.3 Kinetic Power 148

References 3

CHAPTER 4: ENERGY FLOWS

4.1 The Energo-State-Space 156

4.1.1 Energo-State-Trajectories 156

4.1.2 Dissipative and Accumulative Systems 162

4.1.3 Regions of Energy Surface Revisited 166

$\begin{array}{lll}4.2 & \text { The Space of Energo-Events } & 170\end{array}$

$\begin{array}{lll}4.2 .1 & \text { Energo-Motions } & 170\end{array}$

4.2.2 Relative Behaviour of Energy Flows $\quad 174$

$\begin{array}{ll}\text { 4.2.3 Energy Conic Surfaces } & 178\end{array}$

4.3 A Heat Transfer Flow (an Example) 182

$\begin{array}{lr}\text { References } 4 & 186\end{array}$

CHAPTER 5: REVIEW OF THE LIAPUNOV FORMALISM 188-291

5.1 The Liapunov Problem 188

5.1.1 Description 188

5.1.2 Can We Find a Liapunov Function? 192

5.2 Basic Properties 195

5.2.1 Basic Stabilities 195

5.2.2 Conditions for Basic Stabilities 203

5.2.3 Boundedness 208

5.3 Some Extensions 215

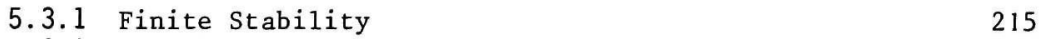

$\begin{array}{ll}\text { 5.3.2 Relative Properties } & 216\end{array}$

$\begin{array}{ll}\text { 5.3.3 Structural Properties } & 219\end{array}$

5.3.4 Total Stability 223

5.4 Quantitative Properties $\quad 228$

5.4.1 Dependent Estimates 228

$\begin{array}{lll}5.4 .2 & \text { Practical Stability } & 237\end{array}$

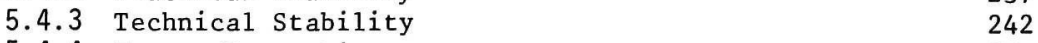

5.4.4 Energo-Properties 251 
5.5 Final and Transient Attractors

5.5.1 Attractors and Final Attractors 254

$\begin{array}{ll}5.5 .2 \text { Conductors } & 260\end{array}$

$\begin{array}{ll}5.6 & \text { Controllability } \\ & 267\end{array}$

5.6.1 Classical Controllability 267

5.6.2 Sufficient Conditions 271

5.6.3 Controllability with Capture 276

5.6.4 Qualitative Controllability 282

References $5 \quad 285$

CHAPTER 6: AUTONOMOUS SYSTEMS 292-409

6.1 The Modular Study 293

6.1.1 Isolated Equilibria 293

6.1.2 Periodic Trajectories $\quad 304$

6.1.3 Invariant Sets 310

6.1.4 Other Trajectories: Isocline Method 322

6.2 The Global Study of Non-Accumulative Systems 325

6.2.1 Global Problems 325

6.2.2 Conservative Systems 328

6.2.3 Passive Systems 333

6.2.4 Too Far East is West: Stabilisation 339

6.3 The Global Study in the General Case 353

6.3.1 Dissipativeness in-the-1arge 355

6.3.2 Global Region of Boundedness 362

6.4 The Local Pattern of Trajectories 366

6.4.1 Region in-the-small 367

6.4.2 Oscillatory Property of Passive Systems 371

6.4.3 Local Study of the General Case 381

6.5 Autonomous Active Physical Systems 389

6.5.1 Self-Sustained Systems 389

6.5.2 Aircraft Wing Flutter 395

References $6 \quad 401$

CHAPTER 7: NONAUTONOMOUS SYSTEMS $\quad$ 410-504

7.1 The Motions in the Space of Events 412

$\begin{array}{lll}7.1 .1 & \text { Input Stimuli } & 412\end{array}$

7.1.2 Motions and Sets 417 
7.2 The Global Pattern of Events $\quad 420$

7.2.1 Dissipativeness in-the-large $\quad 420$

7.2.2 Global Limit Region 426

7.3 The Local Transient Processes $\quad 430$

7.3.1 The Region in-the-small 430

7.3.2 Local Convergence $\quad 432$

7.4 The Transient Processes to Steady States 443

7.4.1 Periodic Limit Motion 443

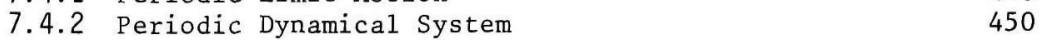

7.4.3 Almost Periodic Limit Motion 453

$\begin{array}{lll}7.5 & \text { The Steady State Processes } & 457\end{array}$

$\begin{array}{lll}7.5 .1 & \text { Frequency Responses } & 457\end{array}$

7.5.2 A Four-Dimensional Case $\quad 464$

7.5.3 Energy Method for PSSP 478

7.6 The Space Version of the Delta Method 480

7.6.1 Development and Description 480

7.6.2 Examples 488

$\begin{array}{ll}\text { References } 7 & 496\end{array}$

CHAPTER 8: KINETIC SYNTHESIS 505-590

8.1 The Fundamental Concepts 505

8.1.1 Subject and the objectives 505

8.1.2 Genesis and Formalization 511

8.1.3 Synthesis for Shape 516

8.1.4 Liapunov System Synthesis $\quad 524$

8.1.5 Liapunov Optimisation 530

8.2 Qualitative Kinetic Synthesis 536

8.2.1 Glider-Pilot Adventure 536

8.2.2 Synthesis for Steady States 539

8.2.3 Synthesis for Oscillations 547

8.3 The Inverse Delta Method 554

8.3.1 Procedure of Inversion $\quad 554$

8.3.2 Plane Examples 558

8.3.3 Examples in State Space 564

$\begin{array}{ll}\text { 8.4 The Design of Regulators } & 571\end{array}$

8.4.1 Automatic Control 571

8.4.2 Damping the Performance Index 578

References $8 \quad 585$

INDEX 